\title{
The design, rationale, and baseline characteristics of a nationwide cohort registry in China: blood pressure and clinical outcome in TIA or ischemic stroke
}

\author{
This article was published in the following Dove Press journal: \\ Patient Preference and Adherence \\ I December 2016 \\ Number of times this article has been viewed
}

\begin{abstract}
Jie $X u^{1,2, *}$
Yi Liu ${ }^{3, *}$

Yongli Tao 4

Xuewei Xie ${ }^{1,2}$

Hongqiu $\mathrm{Gu}^{1,2}$

Yuesong Pan ${ }^{1,2}$

Xingquan Zhao',2

Yongjun Wang ${ }^{1,2}$

Aoshuang Yan ${ }^{3}$

Yilong Wang ${ }^{1,2}$

'Department of Neurology, Beijing

Tiantan Hospital, Capital Medical

University, ${ }^{2}$ China National Clinical

Research Center for Neurological

Diseases, ${ }^{3}$ Department of

Epidemiology and Health Statistics,

School of Public Health, Capital

Medical University, Beijing,

${ }^{4}$ Department of Neurology, First

Affiliated Hospital of Zhengzhou

University, Zhengzhou, China

*These authors contributed equally to this work
\end{abstract}

Correspondence: Yilong Wang Department of Neurology, Beijing

Tiantan Hospital, Capital Medical

University, 6 Tiantan Xili, Dongcheng,

Beijing 100050, China

Tel +861067098350

Email yilong528@aliyun.com

Aoshuang Yan

Department of Epidemiology and Health Statistics, School of Public Health, Capital Medical University, 10 Xitoutiao, You'anmen Wai, Fengtai, Beijing 100069, China

Tel +86 1066131887

Emailyanas@139.com
Background: The relationship between poststroke blood pressure (BP) and clinical outcomes in ischemic stroke (IS) is still controversial. However, there is no large BP database for IS or transient ischemic attack (TIA) in China. This study aims to describe the rationale, study design, and baseline characteristics of a nationwide BP database in IS or TIA patients in China.

Materials and methods: The BOSS (blood pressure and clinical outcome in TIA or ischemic stroke) study was a hospital-based, prospective cohort study aiming to assess BP parameters and clinical outcome in IS/TIA patients. BP parameters were based on office BP, ambulatory $\mathrm{BP}$, and home BP. Clinical outcomes included stroke recurrence, combined vascular events, and disability. Electronic case-report forms were used to record baseline and follow-up data. The patients were followed up for clinical outcomes at 3 months through face-to-face interview and at 12 months by telephone.

Results: Between October 2012 and February 2014, the BOSS registry recruited 2,608 patients from 61 hospitals, with a mean age of 62.5 years, $32.4 \%$ of whom were female, $88.9 \%$ with an entry diagnosis of IS, and $86 \%$ diagnosed with hypertension. The rates of patients lost-tofollow-up were $3.1 \%$ at 3 months and $5.1 \%$ at 1 year; $93 \%$ of patients completed ambulatory BP monitoring during hospitalization and $94.7 \%$ finished a 3-month BP diary.

Conclusion: The BOSS registry will provide important evidence about BP management in the acute phase and secondary prevention for IS/TIA patients.

Keywords: blood pressure, ischemic stroke, transient ischemic attack

\section{Introduction}

Stroke is the second-leading cause of death in the world and the leading cause of death in China. ${ }^{1-4}$ In 2013, more than 1.9 million Chinese adults died from stroke, which represented an increase of $47.7 \%$ from 1.3 million in $1990 .{ }^{4}$ Hypertension is the most important risk factor for stroke. ${ }^{5}$ About $54 \%$ of strokes worldwide were attributable to high blood pressure (BP), and about $80 \%$ of the attributable burden occurred in low- or middle-income countries. ${ }^{6}$ To date, an estimated 0.2 billion people had hypertension in China, accounting for a fifth of the total hypertensive population in the world. The rising incidence of stroke and hypertension has created a heavy burden to the Chinese health care system.

American, ${ }^{7}$ European, ${ }^{8}$ and Japanese ${ }^{9}$ hypertension guidelines have confirmed the importance of ambulatory BP monitoring (ABPM) and home BPM (HBPM). Most studies $^{10-13}$ on stroke still use BP values based on traditional office measurements, 
rather than ABPM or HBPM. Moreover, BP lowering in the acute phase of ischemic stroke (IS) and secondary prevention has been a longstanding controversy. ${ }^{14,15}$ It is not clear when the optimal time is to initiate early BP lowering or what the target-BP level is in IS and transient ischemic attack (TIA) patients. There are few BP databases ${ }^{16,17}$ for IS patients worldwide to date. As far as we know, China, which has a fifth of the world's population, still lacks a BP database for IS and TIA patients. Given this, we performed a nationwide prospective investigation on BP parameters and clinical outcomes in our cohort of patients with acute IS or TIA from 2012 in 61 hospitals, and 1-year follow-up data of all 2,068 patients was completed in 2015. In this report, we introduce the rationale, study design, and the baseline characteristics of BOSS (blood pressure and clinical outcome in TIA or ischemic stroke).

\section{Materials and methods Study design}

BOSS was a nationwide, hospital-based, longitudinal cohort study aiming to assess BP parameters and clinical outcome in IS/TIA patients, conducted at 61 hospitals in China. The participating hospitals were mainly tertiary urban hospitals, selected from 16 provinces and four municipalities across mainland China, including Northeast China (Heilongjiang, Jilin, Liaoning), Northwest China (Shaanxi), North China (Beijing, Tianjin, Hebei, Shanxi, Inner Mongolia), East China (Shanghai, Shandong, Jiangsu, Fujian, Zhejiang), South-central China (Henan, Hubei, Guangdong), and Southwest China (Chongqing, Sichuan). The details of centers are shown in Table S1. A total of 2,720 IS/TIA patients were consecutively enrolled from October 2012 to February 2014. An average of 42.5 participants were enrolled in each center. The study was approved by the central Institutional Review Board at Beijing Tiantan Hospital, and all patients or their designated relatives provided written informed consent. Electronic case-report forms were used to record baseline and follow-up data. The patients were followed up at 3 months through face-to face interview and at 12 months by telephone.

\section{$\mathrm{BP}$ measurement}

Office BP (OBP) was measured by doctors or trained nurses according to a standard measurement method recommended by the American Heart Association ${ }^{18}$ at admission, discharge, and 3-month visit. After enrollment, each patient was assigned a semiautomatic upper-arm BP monitor (HEM-4030; Omron, Kyoto, Japan), and patients or their accompanying relatives were trained by nurses to use it. During hospitalization,
BP would be measured twice daily by patients themselves or their relatives, and BP data were recorded in an assigned hospitalization BP diary. Moreover, ABPM was also completed during hospitalization. BP measurements were taken every 15 minutes during the day and every 30 minutes at night. Daytime episodes were defined from 6 am to 9:59 pm and nighttime episodes from $10 \mathrm{pm}$ to $5: 59 \mathrm{am}$. If the recorded BP readings are less than $80 \%$ of expected measurements, the ABPM should be repeated. Sleep diaries were compiled by patient self-report, including sleep time and awake time. At discharge, the assigned Omron BP monitor was taken home by patients. Patients would persist on measuring BP twice daily at home from the first day after discharge to 3 months after onset, and once a day from 3 months to 12 months after onset, and all BP data were recorded on the assigned home BP diaries (Figure S1). For patients with atrial fibrillation, they did not need to complete ABPM, and all of them were assigned a mercury sphygmomanometer to monitor home $\mathrm{BP}$, rather than a semiautomatic monitor, because oscillometric devices may not record BP accurately in patients with arrhythmias. ${ }^{19,20}$

\section{Inclusion criteria and baseline and follow-up data collection}

Patients were recruited consecutively if the following conditions were met: age of 18 years or older, diagnosis of an acute IS or TIA, and within 7 days of the index event. TIA was defined as new symptomatic neurologic deterioration lasting less than 24 hours with no new infarction on neuroimaging. Acute IS was diagnosed according to World Health Organization criteria combined with brain computed tomography or magnetic resonance imaging confirmation. ${ }^{21}$

A standard electronic data-collection system was developed by Goodwill Information Technology Co Ltd, and the electronic case-report forms were used for baseline and follow-up data collection. All research coordinators and investigators were trained how to use this electronic data-collection system before the trial-kickoff meeting.

Baseline information included demographics, risk factors, medication use, diagnosis, disease management, and discharge status. Risk factors were defined as follows: history of hypertension (a reported history of hypertension or antihypertensive medication use), history of stroke (defined as a medical chart-confirmed history of stroke, including IS, intracerebral hemorrhage, or subarachnoid hemorrhage), coronary heart disease (a reported history of myocardial infarction or cardiac surgery, or with a final diagnosis of myocardial infarction at discharge), atrial fibrillation 
(a reported history of atrial fibrillation or diagnosed using the patient's in-hospital electrocardiogram), diabetes mellitus (self-reported physician diagnosis of diabetes mellitus or use of antidiabetic drugs), dyslipidemia (self-reported physician diagnosis of dyslipidemia or use of lipid-lowering agents), current or previous smoking (defined as an individual who was a smoker at the time of the stroke or had quit smoking within 1 year), moderate or heavy drinking (two or more standard alcoholic beverages consumed per day), body mass index (calculated as measured weight divided by the square of measured height). Other clinical features included prestroke modified Rankin scale (mRS), National Institutes of Health Stroke Scale (NIHSS) score at admission and discharge, IS subtypes according to the TOAST criteria (large-artery atherosclerosis, small-artery occlusion, cardioembolism, stroke of other determined etiology, and stroke of undetermined etiology). Treatment information included medication use during hospitalization and medication with discharge (antiplatelet, anticoagulant, antihypertensive, antidiabetic, and statin medication).

Follow up information included OBP, clinical outcomes, and medication adherence. Clinical outcomes included death, disability, and vascular events. Death was assessed by vascular death (including fatal stroke, fatal myocardial infarction, and other cardiovascular death) or death for any causes. Disability was measured by the mRS from 0 to 5 (death was rated as 6) and was defined as mRS 3-5. Vascular events included stroke or TIA recurrence, myocardial infarction, heart failure, and vascular operation. Recurrent stroke was defined as a new stroke event (ischemic or hemorrhagic) or rapid worsening of an existing focal neurologic deficit lasting more than 24 hours (an increase in the NIHSS score by $\geq 4$ points compared with baseline NIHSS score), accompanied by new ischemic changes on magnetic resonance imaging or computed tomography of the brain. ${ }^{22}$

\section{Statistical analyses}

In this article, analyses focused on patient baseline characteristics and describing the BP parameters. For descriptive analysis, proportions were used for categorical variables, and means with standard deviations were used for continuous variables. Data were analyzed using SAS version 9.1.3 statistical software (SAS Institute, Cary, NC, USA).

\section{Results}

From October 2012 to February 2014, 2,720 IS/TIA patients from 64 hospitals were registered. Three hospitals were eliminated because most of their enrolled patients did not complete ABPM or HBPM, so all 109 patients enrolled in these three hospitals were excluded. Moreover, three patients were removed, because their baseline information were absent. We included a total of 2,608 consecutive patients as our cohort.

We followed up the cohort patients for 1 year; $82(3.1 \%)$ patients were lost to follow-up at 3 months, and 132 (5.1\%) patients were lost to follow-up at 1 year. A detailed patientrecruitment flowchart is illustrated in Figure 1. Of 2,608 patients, the mean age was 62.5 years, $32.4 \%$ were females, $88.9 \%$ had an entry diagnosis of IS, and $86 \%$ was diagnosed with hypertension. Other characteristics are summarized in Table 1.

Table 2 shows the BP parameters based on OBP, ABP, and HBP. Mean OBP was 150.53 $\pm 20.67 / 86.44 \pm 12.58 \mathrm{mmHg}$ at admission, $136.94 \pm 13.89 / 80.29 \pm 9.71 \mathrm{mmHg}$ at discharge, $134.51 \pm 11.94 / 80.52 \pm 8.60 \mathrm{mmHg}$ at the 3 -month visit. Visitto-visit systolic BP (SBP) variability based on OBP was 13.11 $\pm 9.05 \mathrm{mmHg}$, 24-hour SBP variability based on ABPM was $15.35 \pm 4.42 \mathrm{mmHg}$, and day-to-day SBP variability based on HBPM was $8.62 \pm 4.1 \mathrm{mmHg}$. ABP data showed that $70 \%$ of patients had morning hypertension, $51.1 \%$ had nocturnal hypertension, and $27.7 \%$ were reverse dippers.

Medication information is described in Table 3. Proportions of antihypertensive medication during hospitalization, at discharge, and at 3 months were $65.9 \%, 68.5 \%$, and $67.6 \% ; 93 \%$ of patients completed ABP monitoring, $94.7 \%$ of patients completed their 3-month BP diary. Detailed information about ABPM- and BP-diary completion is reported in Table 4. As to clinical outcomes, rates of stroke recurrence, combined vascular events, and mortality are listed in Table 5.

\section{Discussion}

To our knowledge, BOSS is the first nationwide BP database including the most comprehensive BP information for IS/TIA patients in China, and will provide important BP parameters for further investigation in the management of acute IS and secondary prevention of IS. There were three types of BP monitoring in this study: OBPM, ABPM, and HBPM. Because ABPM offers specific advantages over OBPM, such as providing a much larger number of readings, identifying white-coat and masked hypertension phenomena, and supplying nocturnal hypertension and dipping patterns, European Society of Hypertension practice guidelines for $\mathrm{ABPM}^{23}$ point out that ABPM improves prognostic accuracy in target-organ damage and cardiovascular morbidity and mortality compared with OBPM. However, to date most 


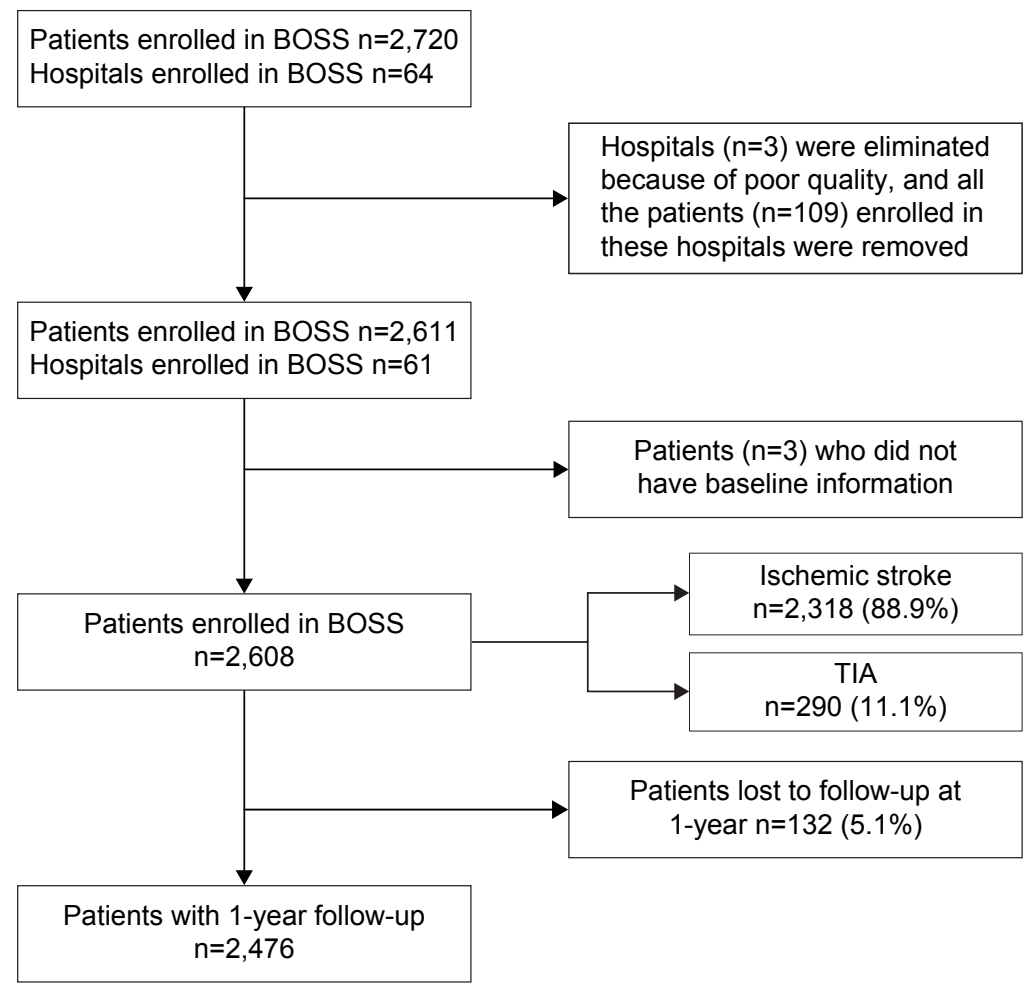

Figure I Patient-recruitment flowchart.

Abbreviations: BOSS, blood pressure and clinical outcome in TIA or ischemic stroke; TIA, transient ischemic attack.

Table I Baseline characteristics of the study population

\begin{tabular}{|c|c|c|}
\hline \multirow[t]{2}{*}{ Variable } & \multirow{2}{*}{$\frac{\text { All }(n=2,608)}{n(\%) / \text { mean } \pm \text { SD }}$} & \multirow{2}{*}{$\frac{\text { Missing }}{\mathrm{n}(\%)}$} \\
\hline & & \\
\hline Stroke subtype & & 0 \\
\hline IS & $2,318(88.9)$ & \\
\hline TIA & $290(11.1)$ & \\
\hline Female & $845(32.4)$ & 0 \\
\hline Age (years) & $62.5 \pm 11.1$ & 0 \\
\hline Current or previous smoker & $\mathrm{I}, 124(43.2)$ & $4(0.2)$ \\
\hline Moderate or heavy drinking & $451(17.3)$ & $4(0.2)$ \\
\hline Body mass index, median ( $\mathrm{Q} \mathrm{I}-\mathrm{Q} 3)$ & $24.6(22.9-26.6)$ & $92(3.5)$ \\
\hline History of hypertension & $\mathrm{I}, 837(70.6)$ & $4(0.2)$ \\
\hline History of stroke & $618(23.8)$ & $6(0.2)$ \\
\hline History of TIA & $102(3.9)$ & $6(0.2)$ \\
\hline Hypertension with discharge diagnosis & $2,238(86)$ & $7(0.3)$ \\
\hline Diabetes mellitus with discharge diagnosis & $739(28.4)$ & $7(0.3)$ \\
\hline Dyslipidemia with discharge diagnosis & $\mathrm{I}, 083(4 \mathrm{I} .7)$ & $8(0.3)$ \\
\hline $\begin{array}{l}\text { Coronary heart disease with discharge } \\
\text { diagnosis }\end{array}$ & $328(12.6)$ & $8(0.3)$ \\
\hline Atrial fibrillation with discharge diagnosis & $104(4)$ & $7(0.3)$ \\
\hline NIHSS score on admission & $3.1 \pm 3.4$ & $49(1.9)$ \\
\hline Ischemic stroke subtype & & $19(0.7)$ \\
\hline Large-artery atherosclerosis & I,358 (59.1) & \\
\hline Cardioembolism & $89(3.9)$ & \\
\hline Small-artery occlusion & $776(33.8)$ & \\
\hline Other & $76(3.3)$ & \\
\hline
\end{tabular}

Abbreviations: IS, ischemic stroke; NIHSS, National Institute of Health Stroke Scale; SD, standard deviation; TIA, transient ischemic attack. stroke studies ${ }^{24-27}$ still use OBPM, and we found that the conclusion of these studies about the relationship between BP level and stroke outcomes remains controversial, especially for IS/TIA patients. It is urgent to establish a large ABPM database in relation to stroke outcome, like IDACO (international database of ambulatory blood pressure in relation to cardiovascular outcome). ${ }^{16}$ BOSS has an independent and complete ABPM database, in which there are $93 \%$ of total patients and more than $85 \%$ of patients with at least $80 \%$ of expected measurements during 24-hour recording.

HBPM is also recommended by guidelines. ${ }^{7-9}$ HBPM seems to be more closely associated with hypertensive end-organ damage than clinic BP, even for a low number of measurements. In BOSS, uniform devices were used to measure home BP to avoid measurement error. In addition, $\mathrm{BP}$ data were recorded on each day, so BP variation could be calculated as day-to-day variability, rather than visit-to-visit variability, which was used in most previous studies. ${ }^{28-30}$ It is worth noting that the completion rate of the 3-month BP diary was as high as $94.7 \%$, which could supply high-quality data to calculate BP parameters.

In addition, adherence to secondary prevention medication in IS and TIA patients was another focus in BOSS. Adherence was defined in consistence with the AVAIL study, ${ }^{31}$ 
Table 2 BP parameters based on OBP, ABP, and HBP

\begin{tabular}{|c|c|c|}
\hline \multirow[t]{2}{*}{ Variable } & \multirow{2}{*}{$\begin{array}{l}\text { All }(n=2,608) \\
\text { Mean } \pm \text { SD }\end{array}$} & \multirow{2}{*}{$\begin{array}{l}\text { Missing } \\
\mathrm{n}(\%)\end{array}$} \\
\hline & & \\
\hline \multicolumn{3}{|l|}{$\overline{\text { OBP }}$} \\
\hline SBP on admission & $150.5 \pm 20.7$ & $50(1.9)$ \\
\hline SBP at discharge & $136.9 \pm 13.9$ & $39(1.5)$ \\
\hline SBP at 3 months & $134.5 \pm 11.9$ & $225(8.6)$ \\
\hline DBP on admission & $86.4 \pm 12.6$ & $50(1.9)$ \\
\hline DBP at discharge & $80.3 \pm 9.7$ & $4 \mid(1.6)$ \\
\hline DBP at 3 months & $80.5 \pm 8.6$ & $225(8.6)$ \\
\hline \multicolumn{3}{|l|}{ Visit-to-visit BP variability } \\
\hline Systolic, mmHg & $13.1 \pm 9.1$ & $17(0.7)$ \\
\hline Diastolic, $\mathrm{mmHg}$ & $7.8 \pm 5.5$ & $17(0.7)$ \\
\hline \multicolumn{3}{|l|}{ ABP } \\
\hline \multicolumn{3}{|l|}{ Average 24-hour BP } \\
\hline Systolic, mmHg & $141.7 \pm 18.2$ & $182(7)$ \\
\hline Diastolic, $\mathrm{mmHg}$ & $84 \pm 13$ & $182(7)$ \\
\hline Average 24-h HR, bpm & $69.9 \pm 9.6$ & $185(7.1)$ \\
\hline \multicolumn{3}{|l|}{ Average daytime BP } \\
\hline Systolic, $\mathrm{mmHg}$ & $143 \pm 18.3$ & $182(7)$ \\
\hline Diastolic, $\mathrm{mmHg}$ & $85.1 \pm 13.3$ & $182(7)$ \\
\hline Average daytime HR, bpm & $71.4 \pm 9.8$ & $185(7.1)$ \\
\hline \multicolumn{3}{|l|}{ Average nighttime BP } \\
\hline Systolic, mmHg & $137.4 \pm 20.4$ & $213(8.2)$ \\
\hline Diastolic, $\mathrm{mmHg}$ & $80.4 \pm 13.4$ & $213(8.2)$ \\
\hline Average nighttime HR, bpm & $64.9 \pm 9.9$ & $216(8.3)$ \\
\hline Morning hypertension, n (\%) & $1,684(70)$ & $204(7.8)$ \\
\hline Nocturnal hypertension, n (\%) & $1,223(51.1)$ & $213(8.2)$ \\
\hline Circadian rhythm & & $213(8.2)$ \\
\hline Extreme dippers, $n(\%)$ & $38(1.6)$ & \\
\hline Dippers, n (\%) & $434(18.1)$ & \\
\hline Nondippers, n (\%) & $1,260(52.6)$ & \\
\hline Reverse dippers, n (\%) & $663(27.7)$ & \\
\hline \multicolumn{3}{|l|}{ 24-hour BP variability } \\
\hline Systolic, mmHg & $15.4 \pm 4.4$ & $183(7)$ \\
\hline Diastolic, $\mathrm{mmHg}$ & $11.6 \pm 4.1$ & $183(7)$ \\
\hline \multicolumn{3}{|l|}{ HBP } \\
\hline \multicolumn{3}{|l|}{ Average BP } \\
\hline Systolic, $\mathrm{mmHg}$ & $134.1 \pm 12.3$ & $139(5.3)$ \\
\hline Diastolic, $\mathrm{mmHg}$ & $79.4 \pm 9.4$ & $139(5.3)$ \\
\hline \multicolumn{3}{|l|}{ Average morning BP } \\
\hline Systolic, mmHg & $134.5 \pm 12.7$ & $142(5.4)$ \\
\hline Diastolic, $\mathrm{mmHg}$ & $79.8 \pm 9.6$ & $142(5.4)$ \\
\hline \multicolumn{3}{|l|}{ Average evening BP } \\
\hline Systolic, $\mathrm{mmHg}$ & $134.5 \pm 12.7$ & $142(5.4)$ \\
\hline Diastolic, $\mathrm{mmHg}$ & $79.8 \pm 9.6$ & $142(5.4)$ \\
\hline \multicolumn{3}{|l|}{ Day-to-day BP variability } \\
\hline Systolic, $\mathrm{mmHg}$ & $8.6 \pm 4.1$ & $139(5.3)$ \\
\hline Diastolic, $\mathrm{mmHg}$ & $7 \pm 7.2$ & $139(5.3)$ \\
\hline
\end{tabular}

Abbreviations: BP, blood pressure; OBP, office BP; $A B P$, ambulatory BP; $\mathrm{HBP}$, home BP; SD, standard deviation; HR, heart rate; SBP, systolic BP; DBP, diastolic BP.

which provided the possibility of comparison of medication adherence of secondary prevention between Chinese and American patients.

Fortunately, the rate of loss to follow-up of BOSS was only $3.1 \%$ at 3 months and $5.1 \%$ at 1 year, which can offer
Table 3 Medication information

\begin{tabular}{|c|c|c|}
\hline \multirow[t]{2}{*}{ Variable } & \multirow{2}{*}{$\frac{\text { All }(n=2,608)}{n(\%)}$} & \multirow{2}{*}{$\begin{array}{l}\text { Missing } \\
\text { n (\%) }\end{array}$} \\
\hline & & \\
\hline \multicolumn{3}{|c|}{ History of medication } \\
\hline Antiplatelet & $544(20.9)$ & $4(0.2)$ \\
\hline Anticoagulant & $14(0.5)$ & $4(0.2)$ \\
\hline Statin & $258(9.9)$ & $4(0.2)$ \\
\hline Antidiabetic & 465 (I7.9) & $4(0.2)$ \\
\hline Antihypertensive & $\mathrm{I}, 416(54.4)$ & $4(0.2)$ \\
\hline \multicolumn{3}{|c|}{ Medication during hospitalization } \\
\hline Antiplatelet & $2,523(97)$ & $7(0.3)$ \\
\hline Anticoagulant & $200(7.7)$ & $8(0.3)$ \\
\hline Statin & $2,332(89.7)$ & $7(0.3)$ \\
\hline Antidiabetic & $650(25)$ & $7(0.3)$ \\
\hline Antihypertensive & I,7। $4(65.9)$ & $8(0.3)$ \\
\hline $\mathrm{CCB}$ & $\mathrm{I}, 340(78.2)$ & \\
\hline ACEI & $286(16.7)$ & \\
\hline ARB & $396(23.1)$ & \\
\hline Diuretic & $113(6.6)$ & \\
\hline$\beta$-Blocker & $135(7.9)$ & \\
\hline Others & $28(1.7)$ & \\
\hline \multicolumn{3}{|c|}{ Medication with discharge } \\
\hline Antiplatelet & $2,434(96.3)$ & $80(3.1)$ \\
\hline Anticoagulant & $29(1.1)$ & $80(3.1)$ \\
\hline Statin & $2,167(85.7)$ & $80(3.1)$ \\
\hline Antidiabetic & $547(21.6)$ & $80(3.1)$ \\
\hline Antihypertensive & $\mathrm{I}, 73 \mathrm{I}(68.5)$ & $80(3.1)$ \\
\hline $\mathrm{CCB}$ & I,337 (77.2) & \\
\hline ACEI & $227(13.1)$ & \\
\hline ARB & $46 \mid(26.6)$ & \\
\hline Diuretic & $108(6.2)$ & \\
\hline$\beta$-Blocker & $182(10.5)$ & \\
\hline Others & $9(0.5)$ & \\
\hline \multicolumn{3}{|c|}{ Medication at 3 months } \\
\hline Antiplatelet & $2,244(94.7)$ & $238(9.1)$ \\
\hline Anticoagulant & $28(I .2)$ & $240(9.2)$ \\
\hline Statin & I,846 (77.9) & $239(9.2)$ \\
\hline Antidiabetic & $485(20.5)$ & $239(9.2)$ \\
\hline Antihypertensive & $\mathrm{I}, 600(67.6)$ & $240(9.2)$ \\
\hline $\mathrm{CCB}$ & $\mathrm{I}, 223(76.4)$ & \\
\hline ACEI & $205(12.8)$ & \\
\hline ARB & $426(26.6)$ & \\
\hline Diuretic & $76(4.8)$ & \\
\hline$\beta$-Blocker & $165(10.3)$ & \\
\hline Others & $8(0.5)$ & \\
\hline
\end{tabular}

Abbreviations: $C C B$, calcium-channel blocker; $A C E I, A C E$ inhibitor; $A R B$, angiotensin-receptor blocker.

credible event outcomes. However, we found the event rate of BOSS to be much lower than historical cohorts, eg, the 1 -year risk of stroke in historical cohorts was $17.7 \%$ in CNSR, ${ }^{24} 12.3 \%$ in CHANCE, ${ }^{32}$ and $12.2 \%$ in SAMMPRIS ${ }^{33}$ compared with $6.1 \%$ in our cohort. It is worth noting that recently the TIAregistry.org project ${ }^{34}$ also reported a very low risk of stroke after a TIA or minor stroke: $3.7 \%$ at 90 days and $5.1 \%$ at 1 year after symptom onset, which is close to our cohort. The lower event rates in our cohort may be explained 
Table 4 ABPM- and BP diary-completion information

\begin{tabular}{|c|c|c|}
\hline Variable & $\frac{\text { All }(n=2,608)}{n(\%)}$ & $\frac{\text { Missing }}{\text { n (\%) }}$ \\
\hline Completion of ABPM & $93 \%$ & \\
\hline Monitoring length (hours) & & $183(7)$ \\
\hline$\geq 24$ & $\mathrm{I}, 192(49.2)$ & \\
\hline$\geq 20,<24$ & $\mathrm{I}, \mathrm{I} 4 \mathrm{I}(47 . \mathrm{I})$ & \\
\hline$\geq 14,<20$ & $54(2.2)$ & \\
\hline$<14$ & $38(1.6)$ & \\
\hline Successful readings & & $183(7)$ \\
\hline$\geq 80 \%$ & $2,144(88.4)$ & \\
\hline$\geq 60 \%,<80 \%$ & $203(8.4)$ & \\
\hline$<60 \%$ & $78(3.2)$ & \\
\hline Including 5-7 am duration & $2,329(96.1)$ & $184(7.1)$ \\
\hline Completion of 3-month BP diary & $94.7 \%$ & \\
\hline Total monitoring length (days) & & $138(5.3)$ \\
\hline$\geq 60,<90$ & $2,363(95.7)$ & \\
\hline$\geq 30,<60$ & $39(1.6)$ & \\
\hline$\geq 7,<30$ & $59(2.4)$ & \\
\hline$<7$ & $9(0.3)$ & \\
\hline
\end{tabular}

Abbreviations: ABPM, ambulatory blood pressure monitoring; BP, blood pressure.

HBPM improving not only BP-medication adherence but also overall compliance with secondary prevention treatment. Our study showed that adherence rates of antiplatelet, statin, and antihypertensive medication use at 3 months were similar to the rates at discharge (see Table 3).

This registry has potential limitations. The first limitation is the different type of device and analysis software for ABPM used in each site. Given this, the original BP data of all of the patients were re-entered in EpiData and all of the BP-composite parameters were recalculated using SAS software. Second, although $94.7 \%$ of patients completed 3-month BP diary in this study, only $40 \%$ of the patients returned their diaries for recording HBP from 3 months to 1 year after symptom onset. Third, telephone but not faceto-face follow-up was adopted at 1 year. For patients with clinical events at 1-year telephone follow-up, we would further confirm this event. Each case fatality was either confirmed on a death certificate from the local citizen

Table 5 Clinical event outcomes

\begin{tabular}{ll}
\hline Outcomes & Event rate, $\mathbf{n}(\%)$ \\
\hline Recurrence rate & $125(4.8)$ \\
3-month & $159(6.1)$ \\
I-year & \\
Combined vascular event rate & $146(5.6)$ \\
3-month & $207(7.9)$ \\
I-year & \\
Mortality & $21(0.8)$ \\
3-month & $51(2)$ \\
I-year &
\end{tabular}

registry or from the attended hospital. In cases of lack of local citizen-registry information or death without hospitalization, case fatality was deemed to be reliable if death was reported on two consecutive follow-up periods from different proxies. We would call back patients with nonfatal events for a face-to-face follow-up or carry out a home visit. Fourth, according to the protocol of this registry, all patients were required to be consecutively enrolled. However, in consideration of HBP monitoring, more mild patients were recruited, which would lead to a selection bias. Fifth, this was a mainly ethnically Chinese cohort, which did not include white and black people.

\section{Conclusion}

This study introduced the design, rationale, and baseline characteristics of BOSS, which was a nationwide, hospital-based, longitudinal cohort study aiming to assess BP parameters (based on OBPM, ABPM, and HBPM) and clinical outcome in IS/TIA patients. The BOSS registry will provide important evidence about BP management in the acute phase and secondary prevention for IS/TIA patients.

\section{Acknowledgments}

Thanks to the top three hospitals that enrolled the most cases for the BOSS study: Xi'an 141 Hospital (Qiuwu Liu), Changzhi People's Hospital (Lili Zhao), and the First Affiliated Hospital of Zhengzhou University (Yuming Xu). The study was supported by grants from the Ministry of Science and Technology of the People's Republic of China (2011BAI08B01 and 2013BAI09B03) and a grant from Beijing Municipal Administration of Hospitals' Youth Program (QML2015 0504). This study was also funded by AstraZeneca, which did not participate in the proposal design, implementation, or statistical analysis.

\section{Disclosure}

The authors report no conflicts of interest in this work.

\section{References}

1. Global Burden of Disease Study 2013 Collaborators. Global, regional, and national incidence, prevalence, and years lived with disability for 301 acute and chronic diseases and injuries in 188 countries, 1990-2013: a systematic analysis for the Global Burden of Disease Study 2013. Lancet. 2015;386(9995):743-800.

2. Feigin VL, Krishnamurthi RV, Parmar P, et al. Update on the Global Burden of Ischemic and Hemorrhagic Stroke in 1990-2013: the GBD 2013 study. Neuroepidemiology. 2015;45(3):161-176.

3. Yang G, Wang Y, Zeng Y, et al. Rapid health transition in China, 1990-2010: findings from the Global Burden of Disease Study 2010. Lancet. 2013;381(9882):1987-2015.

4. Zhou M, Wang H, Zhu J, et al. Cause-specific mortality for 240 causes in China during 1990-2013: a systematic subnational analysis for the Global Burden of Disease Study 2013. Lancet. 2016;387(10015):251-272. 
5. O’Donnell MJ, Xavier D, Liu L, et al. Risk factors for ischaemic and intracerebral haemorrhagic stroke in 22 countries (the INTERSTROKE study): a case-control study. Lancet. 2010;376(9735):112-123.

6. Lawes CM, Vander Hoorn S, Rodgers A. Global burden of bloodpressure-related disease, 2001. Lancet. 2008;371(9623):1513-1518.

7. James PA, Oparil S, Carter BL, et al. 2014 Evidence-based guideline for the management of high blood pressure in adults: report from the panel members appointed to the Eighth Joint National Committee (JNC 8). JAMA. 2014;311(5):507-520.

8. ESH/ESC Task Force for the Management of Arterial Hypertension. 2013 Practice guidelines for the management of arterial hypertension of the European Society of Hypertension (ESH) and the European Society of Cardiology (ESC). J Hypertens. 2013;31(10):1925-1938.

9. Shimamoto K, Ando K, Fujita T, et al. The Japanese Society of Hypertension guidelines for the management of hypertension (JSH 2014) Hypertens Res. 2014;37(4):253-390.

10. He J, Zhang Y, Xu T, et al. Effects of immediate blood pressure reduction on death and major disability in patients with acute ischemic stroke: the CATIS randomized clinical trial. JAMA. 2014;311(5):479-489.

11. Robinson TG, Potter JF, Ford GA, et al. Effects of antihypertensive treatment after acute stroke in the Continue or Stop Post-Stroke Antihypertensives Collaborative Study (COSSACS): a prospective, randomised open, blinded-endpoint trial. Lancet Neurol. 2010;9(8):767-775.

12. Benavente OR, Coffey CS, Conwit R, et al. Blood-pressure targets in patients with recent lacunar stroke: the SPS3 randomised trial. Lancet. 2013;382(9891):507-515.

13. Bath PM, Woodhouse L, Scutt P, et al. Efficacy of nitric oxide, with or without continuing antihypertensive treatment, for management of high blood pressure in acute stroke (ENOS): a partial-factorial randomised controlled trial. Lancet. 2015;385(9968):617-628.

14. Saver JL. Blood pressure management in early ischemic stroke. JAMA. 2014;311(5):469-470.

15. Rothwell PM. Blood pressure in acute stroke: which questions remain? Lancet. 2015;385(9968):582-585.

16. Thijs L, Hansen TW, Kikuya M, et al. The international database of ambulatory blood pressure in relation to cardiovascular outcome (IDACO): protocol and research perspectives. Blood Press Monit. 2007; 12(4):255-262.

17. Niiranen TJ, Thijs L, Asayama K, et al. The international database of home blood pressure in relation to cardiovascular outcome (IDHOCO): moving from baseline characteristics to research perspectives. Hypertens Res. 2012;35(11):1072-1079.

18. Pickering TG, Hall JE, Appel LJ, et al. Recommendations for blood pressure measurement in humans: an AHA scientific statement from the Council on High Blood Pressure Research Professional and Public Education Subcommittee. J Clin Hypertens. 2005;7(2):102-109.
19. Stergiou GS, Parati G, Asmar R, O’Brien E. Requirements for professional office blood pressure monitors. J Hypertens. 2012;30(3):537-542.

20. Myers MG, Stergiou GS. Should oscillometric blood pressure monitors be used in patients with atrial fibrillation? J Clin Hypertens (Greenwich). 2015;17(7):565-566.

21. [No authors listed]. Stroke - 1989: recommendations on stroke prevention, diagnosis, and therapy. Stroke. 1989;20(10):1407-1431.

22. Wang Y, Wang Y, Zhao X, et al. Clopidogrel with aspirin in acute minor stroke or transient ischemic attack. N Engl J Med. 2013;369(1): 11-19.

23. Parati G, Stergiou G, O’Brien E, et al. European Society of Hypertension practice guidelines for ambulatory blood pressure monitoring. J Hypertens. 2014;32(7):1359-1366.

24. Wang Y, Xu J, Zhao X, et al. Association of hypertension with stroke recurrence depends on ischemic stroke subtype. Stroke. 2013;44(5): 1232-1237.

25. Odden MC, McClure LA, Sawaya BP, et al. Achieved blood pressure and outcomes in the Secondary Prevention of Small Subcortical Strokes Trial. Hypertension. 2016;67(1):63-69.

26. Benavente OR, Hart RG, McClure LA, et al. Effects of clopidogrel added to aspirin in patients with recent lacunar stroke. $N$ Engl J Med. 2012;367(9):817-825

27. Lin MP, Ovbiagele B, Markovic D, Towfighi A. Systolic blood pressure and mortality after stroke: too low, no go? Stroke. 2015;46(5):1307-1313.

28. Rothwell PM, Howard SC, Dolan E, et al. Prognostic significance of visit-to-visit variability, maximum systolic blood pressure, and episodic hypertension. Lancet. 2010;375(9718):895-905.

29. Nagai M, Kario K. Visit-to-visit blood pressure variability, silent cerebral injury, and risk of stroke. Am J Hypertens. 2013;26(12):1369-1376.

30. Rossignol P, Cridlig J, Lehert P, Kessler M, Zannad F. Visit-to-visit blood pressure variability is a strong predictor of cardiovascular events in hemodialysis: insights from FOSIDIAL. Hypertension. 2012;60(2): 339-346.

31. Bushnell C, Zimmer L, Schwamm L, et al. The adherence evaluation after ischemic stroke longitudinal (AVAIL) registry: design, rationale, and baseline patient characteristics. Am Heart J. 2009;157(3):428-435.e2.

32. Wang Y, Pan Y, Zhao X, et al. Clopidogrel with aspirin in acute minor stroke or transient ischemic attack (CHANCE) trial: one-year outcomes. Circulation. 2015;132(1):40-46.

33. Chimowitz MI, Lynn MJ, Derdeyn CP, et al. Stenting versus aggressive medical therapy for intracranial arterial stenosis. $N$ Engl J Med. 2011;365(11):993-1003.

34. Sacco RL, Rundek T. The value of urgent specialized care for TIA and minor stroke. N Engl J Med. 2016;374(16):1577-1579. 


\section{Supplementary materials}

Table SI Participating hospital information

\begin{tabular}{|c|c|c|c|}
\hline Location & Name & Grade & $\mathbf{P I}$ \\
\hline \multicolumn{4}{|l|}{ North China } \\
\hline Beijing & Beijing Tiantan Hospital, Capital Medical University & III & Xingquan Zhao \\
\hline Beijing & Beijing An Zhen Hospital, Capital Medical University & III & $\mathrm{Qi} \mathrm{Bi}$ \\
\hline Beijing & Beijing Friendship Hospital & III & Jimei Li \\
\hline Beijing & Third Hospital of Peking University & III & Dongsheng Fan \\
\hline Beijing & Beijing Hospital & III & Tao Gong \\
\hline Beijing & People's Hospital of Peking University & III & Xuguang Gao \\
\hline Hebei & Second Hospital of Hebei Medical University & III & Guohua Zhang \\
\hline Hebei & First Hospital of Handan & III & Yiping Wu/Jie Lin \\
\hline Hebei & Cangzhou Central Hospital & III & Junling Zhang \\
\hline Hebei & Shijiazhuang Central Hospital & III & Wanying Shi \\
\hline Hebei & Third Hospital of Hebei Medical University & III & Junyan Liu \\
\hline Hebei & People's Hospital of Hebei & III & Peiyuan Lv \\
\hline Inner Mongolia & Baogang Hospital & III & Dong Wang \\
\hline Shanxi & Second Hospital of Shanxi Medical University & III & Guanglai Li \\
\hline Shanxi & Changzhi People's Hospital & III & Lili Zhao \\
\hline Tianjin & Fourth Central Hospital of Tianjin & III & Chunling Ji \\
\hline Tianjin & Tianjin Huanhu Hospital & III & Yong Ji \\
\hline Tianjin & Tianjin Binhai People's Hospital & $\|$ & Bin Li \\
\hline \multicolumn{4}{|c|}{ Northeast China } \\
\hline Heilongjiang & First Machine Factory Workers Hospital of Qiqihar & ॥ & Chunling Yang \\
\hline Jilin & Jilin Central Hospital & III & Hanyi Zhang \\
\hline Jilin & First Hospital of Jilin University & III & Jiachun Feng \\
\hline Liaoning & First Hospital of Liaoning Medical University & III & Rubo Sui \\
\hline Liaoning & Hospital of Dalian Economic and Technological Development Zone & ॥ & Ying Lian \\
\hline \multicolumn{4}{|c|}{ Northwest China } \\
\hline Shaanxi & Xi'an I4I Hospital & II & Qiuwu Liu \\
\hline \multicolumn{4}{|l|}{ East China } \\
\hline Fujian & Xiamen Second Hospital & III & Jianping Niu \\
\hline Jiangsu & First Hospital of Suzhou University & III & Zhuan Xu \\
\hline Jiangsu & Second Hospital of Suzhou University & III & Heqing Zhao \\
\hline Jiangsu & Nanjing First Hospital & III & Junshan Zhou \\
\hline Jiangsu & Lianyungang Traditional Chinese Medicine Hospital & III & Lejun Li \\
\hline Jiangsu & Gulou Hospital of Nanjing University Medical College & III & Zhongyuan Wang \\
\hline Shandong & People's Hospital of Zibo Linzi & III & Yongliang Cao \\
\hline Shandong & Affiliated Hospital of Qingdao University & III & Xudong Pan \\
\hline Shandong & Hospital of Shandong Province & III & Yifeng Du \\
\hline Shanghai & East Hospital of Yangpu District & ॥ & Fei Li \\
\hline Shanghai & Shanghai Tongji Hospital & III & Zhiyu Nie \\
\hline Shanghai & Central Hospital of Shanghai Yangpu & III & Xin Li \\
\hline Shanghai & Sixth People's Hospital of Shanghai Jiaotong University & III & Xiaojiang Sun \\
\hline Shanghai & Branch of Shanghai First People's Hospital & $\|$ & Shaoshi Wang \\
\hline Shanghai & Public Hospital of Shanghai Pudong New Area & $\|$ & Xuelian Yang \\
\hline Shanghai & Xinhua Hospital of Shanghai Jiaotong University Medical Department & III & Zhenguo Liu \\
\hline Shanghai & Ruijin Hospital of Shanghai Jiaotong University Medical Department & III & Shengdi Chen \\
\hline Zhejiang & First People's Hospital of Taizhou & III & Zhimin Wang \\
\hline Zhejiang & First Hospital of Wenzhou Medical University & III & Chengye Zhou \\
\hline Zhejiang & First Hospital of Zhejiang University Medical College & III & Benyan Luo \\
\hline Zhejiang & Hangzhou First Hospital & III & Guozhong Niu \\
\hline Zhejiang & Shaoyifu Hospital of Zhejiang University Medical College & III & Xingyue Hu \\
\hline Zhejiang & No 2 Hospital of Zhejiang University Medical College & III & Baorong Zhang \\
\hline
\end{tabular}

(Continued) 
Table SI (Continued)

\begin{tabular}{|c|c|c|c|}
\hline Location & Name & Grade & $\mathbf{P I}$ \\
\hline \multicolumn{4}{|c|}{ South-central China } \\
\hline Guangdong & Jiangmen Central Hospital & III & Jianxin Zhong \\
\hline Guangdong & First Hospital of Jinan University & III & Anding $\mathrm{Xu}$ \\
\hline Guangdong & First People's Hospital of Foshan & III & Yukai Wang \\
\hline Guangdong & First People's Hospital of Guangzhou & III & Xiaoping Pan \\
\hline Guangdong & Third Hospital of Zhongshan University & III & Zhengqi Lu \\
\hline Guangdong & Zhujiang Hospital & III & Zhenhua Liu \\
\hline Guangdong & People's Hospital of Shenzhen & III & Xiaofan Chu \\
\hline Henan & First Hospital of Zhengzhou University & III & Yuming $\mathrm{Xu}$ \\
\hline Hubei & Wuhan Union Hospital, Tongji Medical College of HUST & III & Yuanjin Guo \\
\hline Hubei & Wuhan Neurosurgical Hospital & III & Yuhua Chen \\
\hline Hubei & Wuhan First Hospital & III & Guohua Chen \\
\hline Hubei & Wuhan Zhongshan Hospital & III & Xiaorong Deng \\
\hline Hubei & Xinhua Hospital of Hubei & III & Kang Xu \\
\hline \multicolumn{4}{|c|}{ Southwest China } \\
\hline Sichuan & Third People's Hospital of Chengdu & III & li Gao \\
\hline Sichuan & People's Hospital of Sichuan & III & Wenbin Wu \\
\hline Chongqing & Daping Hospital of Third Military Medical University & III & Huadong Zhou \\
\hline Chongqing & First Hospital of Third Military Medical University & III & Kangning Chen \\
\hline
\end{tabular}

Abbreviations: PI, principal investigator; HUST, Huazhong University of Science and Technology.

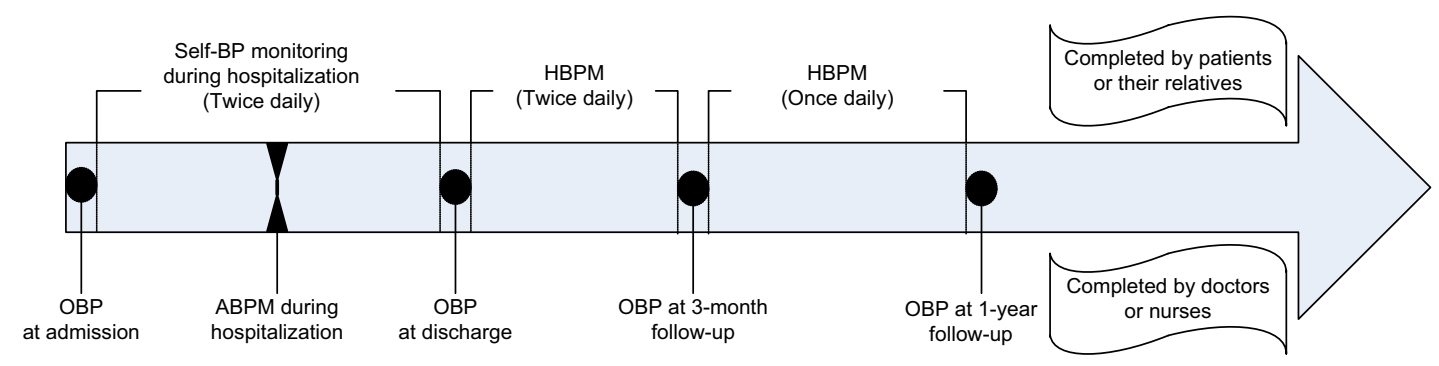

The design of the BOSS study

Figure SI Design of the BOSS study.

Abbreviations: BOSS, blood pressure and clinical outcome in TIA or ischemic stroke; BP, blood pressure; OBP, office BP; ABPM, ambulatory BP monitoring; HBPM, home BPM; TIA, transient ischemic attack.

\section{Publish your work in this journal}

Patient Preference and Adherence is an international, peer-reviewed, open access journal that focuses on the growing importance of patient preference and adherence throughout the therapeutic continuum. Patient satisfaction, acceptability, quality of life, compliance, persistence and their role in developing new therapeutic modalities and compounds to optimize clinical outcomes for existing disease states are major areas of interest for the journal. This journal has been accepted for indexing on PubMed Central. The manuscript management system is completely online and includes a very quick and fair peer-review system, which is all easy to use. Visit http://www. dovepress.com/testimonials.php to read real quotes from published authors.

\footnotetext{
Submit your manuscript here: http://www.dovepress.com/patient-preference-and-adherence-journal
} 